\section{Military Technical College Kobry El-Kobbah, Cairo, Egypt.}

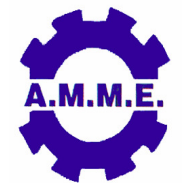

$15^{\text {th }}$ International Conference on Applied Mechanics and Mechanical Engineering.

\title{
REMOTE OPERATED TRACKED VEHICLE FUEL PEDAL ACTUATOR PERFORMANCE
}

\author{
M. Atef*, M. A. Elhaddad**, R. H. Khodary* and A. E. Eliewa*
}

\begin{abstract}
In recent years, there has been a great interest worldwide in the development of Autonomous Ground Vehicle System (AGVS) technologies due to their potential in civil and military applications.

This paper presents an effective algorithm to control the speed of a tracked vehicle. This is part of a larger control system that converts a manual driving vehicle into a remotely one. To achieve this goal an electronically controlled module is proposed, realized and implemented on the fuel pedal. The necessary sensors and actuators have been added to the conventional vehicle. These sensors and actuators have been selected according to the design diagram of vehicle control system and system calculations where the LabVIEW software is used as base environment for implementation of the system controller as well as the development of the control algorithm.
\end{abstract}

For investigation of the implemented fuel pedal control system, a dynamic model is developed and the simulation results were found to agree to a great extent with the real test results.

\section{KEY WORDS}

Unmanned systems, Electronic control, speed control.

* Egyptian Armed Forces.

** Associate Professor, Dept. of Automotive Engineering, Higher Institute of Technology, 10th of Ramadan, Egypt. 


\section{NOMENCLATURE}

A ... Restriction areas, $\mathrm{m}^{2}$

$A_{A} \ldots$ Piston area of cab side, $m^{2}$

$A_{B} \ldots$ Piston area of rod side, $\mathrm{m}^{2}$

$A_{r} \ldots$ Radial clearance area, $m^{2}$

B Bulk modulus

$\mathrm{C}_{\mathrm{d}} \ldots$ Discharge coefficient

c ... Spool radial clearance, $m$

$\mathrm{F}_{\text {Aseat }}$ Actuator seat reaction force, $\mathrm{N}$.

$\mathrm{F}_{\mathrm{L}} \ldots$ Load force, $\mathrm{N}$

$F_{S} \ldots$ Solenoid force, $(\mathrm{N})$

$f_{\text {Aseat }}$ Actuator seat friction coefficient.

$f_{c} \ldots$ Coefficient of total resistance

$f_{p} \ldots \quad$ Piston friction coefficient, Ns/m

$\mathrm{f}_{\mathrm{s}} \ldots \quad$ Friction coefficient, $\mathrm{Ns} / \mathrm{m}$

G ... Weight of vehicle, ton

g... Gravitational acceleration, $\mathrm{m} / \mathrm{s}^{2}$

h ... Throttle displacement, $\mathrm{m}$

$k$... Spool spring stiffness, $N / m$

$\mathrm{K}_{\text {Aseat }}$ Actuator seat stiffness, $\mathrm{N} / \mathrm{m}$.

$k_{\text {Dimensionless coefficient of self }}$

- regulation

m ... Spool mass, $\mathrm{kg}$

N ... Load settings

$\mathrm{P}_{\mathrm{S}} \ldots$ Supply pressure, $\mathrm{Pa}$

$\mathrm{P}_{\mathrm{t}} \ldots \quad$ Return pressure, $\mathrm{Pa}$

p ... Percentage of engine power

output to the maximum
Q Flow rate, $\mathrm{m}^{3} / \mathrm{s}$

$Q_{P} \quad$ Pump flow rate

$Q_{a} \quad$ The actual flow rate of the pump

$Q_{c} \quad$ Cap flow rate, $\mathrm{m}^{3} / \mathrm{s}$

$\mathrm{Q}_{\mathrm{e}} \quad$ External leakage flow rate, $\mathrm{m}^{3} / \mathrm{s}$

$Q_{i} \quad$ Internal leakage flow rate, $\mathrm{m}^{3} / \mathrm{s}$

$Q_{r} \quad$ Rod flow rate, $\mathrm{m}^{3} / \mathrm{s}$

$q_{\text {I }} \quad$ The internal leakage of the pump

$R_{e} \quad$ Resistance to external leakage

$R_{i} \quad$ Resistance to internal leakage

$\mathrm{T}_{\mathrm{e}} \quad$ Time of prime mover, sec

$T_{\text {I }} \quad$ Load torque, N.m

$\mathrm{T}_{\mathrm{o}} \quad$ Steady state value of engine torque,

$\mathrm{T}_{\text {lo }} \quad$ Steady state value of engine torque

$v_{P} \quad$ Piston velocity, $\mathrm{m} / \mathrm{s}$

Volume of oil filling the cylinder at cab side, $\mathrm{m}^{3}$

volume of oil filling the cylinder at rod side, $\mathrm{m}^{3}$

$V_{\text {Ao }}$ Initial volume of the cab side, $\mathrm{m}^{3}$

$\mathrm{V}_{\mathrm{Bo}}$ Initial volume of the rod side, $\mathrm{m}^{3}$

x Displacement, $\mathrm{m}$

y

Percentage of the accelerator position to the maximum

$\omega \quad$ Width of the port, $m$

$\omega_{2} \quad$ Angular velocity of crankshaft

$\omega_{0}$ steady - state value of angular velocity of crank shaft, $\mathrm{rad} / \mathrm{sec}$

$\theta_{\mathrm{e}}$
Dimensionless coefficient of load setting gain

\section{INTRODUCTION}

In recent years, there has been a great interest worldwide in the development of Autonomous Ground Vehicle System (AGVS) technologies due to their potential in civil and military applications [1].

This development is done by implementing a control system which has the objective to make the tracked vehicle follow the commanded speed and heading rate (steering angular velocity). A tracked vehicle is a highly complicated non-linear and uncertain system that involves many mechanical systems, such as a diesel engine, gear and 
transmission, steering differential unit, track/soil interaction and brake systems [2]. There are several attempts have been made to address various issues for the control of tracked vehicles [[3]-[8]].

Atef, et al. modifies the tracked vehicle conventional driving system to be remotely controlled. To achieve this goal an electronically controlled module is proposed. All details of the proposed control system including design of the actuators, sensors selection, control program flowcharts, Lab VIEW interfacing between the vehicle and the remote control station, designing the interfacing circuits and finally mathematical modeling and simulation of the control system to check its response are presented in $[9,10]$.

This paper presents the stages of implementation of the fuel pedal control system. These stages include designing and realization of different modules of the hardware and assembly of the mechanical, electrical and electronic subsystems.

A proposed control system is implemented, the needed sensors are added, the hydraulic system is assembled and finally the control algorithm is built to close the loop using LabVIEW software. Data Acquisition Card (DAQ) is used for interfacing between sensors, actuators and LabVIEW. For assessment of system behavior; system model is established where its output is compared to constructed actual system.

\section{SYSTEM DESCRIPTION}

The proposed fuel pedal control system consists of the actuator (a hydraulic subsystem which actuate the pedal), and a controller (a subsystem which consists of a control unit, sensors, and interfacing circuits). Figure 1 shows a block diagram of the accelerator pedal control system. The controller is designed to deliver the prescribed actuating signal to the hydraulic subsystem according to the input signal. The hydraulic subsystem actuates the accelerator pedal according to the input signal (the desired speed). The necessary sensors are added to detect the output signal, the measured feedback signal is the engine crankshaft speed that given by a DC tachometer, and the pedal displacement using a linear variable differential transformer (LVDT).

\section{Hydraulic System Setup}

The proposed hydraulic system serves as actuator for the proposed control system and it consists of the following parts; the hydraulic pump, a Proportional Directional Control Valve (PDCV), hydraulic cylinder, relief valve and the oil tank. Figure 2 shows the designed hydraulic circuit.

\section{Hydraulic pump}

The hydraulic pump is the source of hydraulic power to the system. The hydraulic oil is fed to the actuator via the proportional directional control valve. The pump is driven by integrated DC motor with voltage (12 VDC) taken from a vehicle batteries. Figure 3 shows the pump and its driving motor. 


\section{Proportional directional control valve}

The proportional directional control valve (P.D.C.V) is used to direct the fluid flow from the pump to extend or retract the hydraulic cylinder that is connected to the pedal. The valve supply voltage is a 24VDC that is supplied from the vehicle batteries. The control command signal is $0: \pm 10$ VDC that is controlled by a controller.

The P.D.C.V is equipped with a built in controller that combines all necessary functions for the optimal operation of valve. It takes the voltage supply signal and the command signal. The controller has a built in feedback to the spool displacement and position, the control circuit of the P.D.C.V is shown in Fig. 4.

The pins A, B are connected to the vehicle's batteries; pins D, E are the input pins of the command signal, these pins are connected to the analogue output channel 0 (AO 0 ) of the data acquisition card (DAQ), pins $C, F$ are connected to the analogue input channel 0 (Al 0$)$ of the DAQ, to measure the spool stroke. Figure 5 shows the implementation of the P.D.C.V.

\section{Hydraulic cylinder}

The hydraulic cylinder is fixed from its cap end in vehicle chassis, and the rod end is connected to the fuel pedal to make the same function of the driver (increasing and decreasing speed). The cylinder is actuated by the hydraulic pressure energy. The setup of hydraulic system with the accelerator pedal is shown in Fig. 6 .

\section{Relief valve}

The function of relief valve is to set the maximum pressure in a hydraulic system. When the pressure control valve is closed the inlet and outlet ports are isolated by the valve spool. The valve inlet port connects with the pump outlet, while the outlet port (Port P) connects with a P.D.C.V inlet port, and port T connects to the oil tank. Figure 7 shows the valve and its connections with the other parts of the system.

\section{Sensors Implementation}

In order to control the fuel pedal control system operation, the input fuel pedal displacement and the required engine r.p.m must be compared with the actual pedal displacement and the corresponding engine r.p.m. Then sensing the pedal rectilinear displacement and engine r.p.m is necessary to close the loop of control system.

\section{Engine rpm sensor}

The rpm sensor used is a DC tachometer that works with same principle of generator. In the original vehicle, the rpm indicator that is located in the driver panel is driven by a tachometer that fixed to the engine flywheel. We use this tachometer and fix its wire that is connected to the rpm indicator, to the DC tachometer. An adaptor is made to connect that wire with the DC tachometer. As the engine runs, the wire rotates and consequently the DC tachometer and a potential difference is induced, measured, and sent to the controller as feedback of engine rpm.

The DC tachometer is fixed below the driver panel, and the DC tachometer and its adaptation with the wire of tachometer is shown in Fig. 8. The output signal of the $\mathrm{DC}$ tachometer is sent to the analogue input channel 4 (Al 4) of the DAQ. 


\section{Displacement sensor}

The displacement sensor used is a linear variable differential transformer (LVDT), with a supply power 15: 30 VDC. It takes its input from the vehicle batteries. The LVDT is connected to the fuel pedal and the output signal is sent to the analogue input channel 5 (AI 5) of the DAQ. Figure 9 shows the LVDT and its connection to the pedal.

\section{Pressure sensor}

Piezoelectric pressure sensor is used to measure the pressure of the pump supply line, this sensor is mounted and adapted to the pressure line using a threaded T shaped connector and a high pressure hoses at the inlet port of the relief valve. The output signal of sensor is sent to channel 2 of the analogue input channels of the data acquisition card (AI 2).

\section{LabVIEW Interface with Data Acquisition Card (DAQ)}

The acquisition of the actual engine speed signal and accelerator pedal displacement and the generation of the reference speed signal are performed using a PC with LabVIEW software and a data acquisition (DAQ) card. Experimental control algorithm is written in LabVIEW. The actual speed is taken from the signal generated by the DC tachometer, and the actual accelerator pedal displacement is taken from the LVDT output signal. These signals are acquired using the DAQ card and converted to rpm and displacement with a data analysis program written in LabVIEW. The reference speed signal is generated by a LabVIEW program. The used DAQ is NI 6221. Figure 10 shows the connection of the PC with the DAQ and Figure 11 shows the front panel of the signal acquisition program.

\section{SYSTEM MODELING}

The modeling of accelerator pedal control system; can be divided into hydraulic subsystem, mechanical subsystem and controller. The hydraulic subsystem consists of a pump, a proportional directional control valve that controls the oil direction to the hydraulic cylinder that is the actuator connected to the fuel pedal. The mechanical subsystem consists of the fuel pedal with its mechanical linkages and the engine.

As shown here, there are a lot of parameters included in the fuel pedal control system model. So MATLAB® SIMULINK was used to model the equations governing the operation of the system.

\section{Hydraulic Subsystem Mathematical Modeling}

The input to the subsystem is the flow rate of fluid supplied by the pump, and the output is the cylinder displacement. The following assumptions were made in modeling the hydraulic system; there is no pressure drop in the fluid transmission lines between the pump and valve and between the valve and cylinder, the wave dynamics on the fluid transmission lines are neglected, the bulk modulus of fluid is considered constant, there is no leakage at the piston-cylinder interface and the back pressure dynamics are negligible. 
The governing equations of the hydraulic subsystem are [10] [11]:

Displacement of the valve spool:

$$
F_{S}=m x "+f_{S} x+k_{S} x
$$

Flow equations through valve restriction areas:

$$
\begin{aligned}
Q_{a} & =C_{d} A_{a}(x) \sqrt{\frac{2}{\rho}\left(P_{A}-P_{t}\right)} \\
Q_{b} & =C_{d} A_{b}(x) \sqrt{\frac{2}{\rho}\left(P_{S}-P_{A}\right)} \\
Q_{c} & =C_{d} A_{c}(x) \sqrt{\frac{2}{\rho}\left(P_{S}-P_{B}\right)} \\
Q_{d} & =C_{d} A_{d}(x) \sqrt{\frac{2}{\rho}\left(P_{B}-P_{t}\right)}
\end{aligned}
$$

For $x \geq 0$

$$
\begin{aligned}
& A_{a}=A_{c}=\omega \sqrt{\left(x^{2}+c^{2}\right)} \\
& A_{b}=A_{d}=A_{r}=\omega c
\end{aligned}
$$

For $\mathrm{x} \leq 0$

$$
\begin{aligned}
& A_{a}=A_{c}=A_{r}=\omega c \\
& A_{b}=A_{d}=\omega \sqrt{\left(x^{2}+c^{2}\right)}
\end{aligned}
$$

Continuity equation applied to the cylinder chambers:

$$
\begin{gathered}
Q_{A}-A_{A} \frac{d y}{d t}-Q_{i}-Q_{e A}=\frac{V_{A}}{B}\left(\frac{d P_{A}}{d t}\right) \\
A_{B} \frac{d y}{d t}+Q_{i}-Q_{B}-Q_{e B}=\frac{V_{B}}{B}\left(\frac{d P_{B}}{d t}\right)
\end{gathered}
$$

The flow rates of $Q A$ and $Q B$ are given by:

$$
\begin{aligned}
& Q_{A}=Q_{b}-Q_{a} \\
& Q_{B}=Q_{d}-Q_{c}
\end{aligned}
$$

The volumes VA and VB are given by:

$$
V_{A}=V_{A_{o}}+A_{A} y
$$




$$
V_{B}=V_{B_{o}}-A_{B} y
$$

Assuming that the leakage flow rate is linearly proportional to the pressure difference, the leakage flow rates could be given by the following relations:

$$
\begin{aligned}
& Q_{i}=\left(P_{A}-P_{B}\right) / R_{i} \\
& Q_{e A}=P_{A} / R_{e} \\
& Q_{e B}=P_{B} / R_{e}
\end{aligned}
$$

Equation of motion of piston:

$$
\begin{aligned}
& P_{A} A_{A}-P_{B} A_{B}+F_{L}=m_{P} \frac{d^{2} y}{d t^{2}}+f_{P} \frac{d y}{d t}+F_{\text {Aseat }} \\
& F_{\text {Aseat }}= \begin{cases}K_{\text {Aseat }}\left(y-y_{\text {max }}\right)+f_{\text {Aseat }} \frac{\mathrm{dy}}{\mathrm{dt}} & \text { for } \quad \mathrm{y} \geq \mathrm{y}_{\max } \\
0 & \text { for } \mathrm{y}_{\min } \leq \mathrm{y} \geq \mathrm{y}_{\max } \\
K_{\text {Aseat }}\left|y-y_{\min }\right|+f_{\text {Aseat }} \frac{\mathrm{dy}}{\mathrm{dt}} & \text { for } \mathrm{y} \leq \mathrm{y}_{\min }\end{cases}
\end{aligned}
$$

All the above equations were used in the hydraulic subsystem simulink model as shown in Fig. 12.

\section{Mechanical Subsystem Mathematical Modeling}

The input of subsystem is the fuel pedal displacement (that equals to the piston displacement), and the output is the engine rpm. A mathematical model describes the dynamic behavior of engine with regard to all parameters affecting the operation of engine are as follow: [10] [12].

The steady state operation of engine is characterized by the combination of engine power $\left(N_{e}\right)$, engine torque $(T)$, engine r.p.m $\left(n_{e}\right)$, boost pressure $\left(P_{b}\right)$, specific fuel consumption $\left(g_{e}\right)$, air fuel ratio $(\alpha)$ and engine efficiency $\left(\eta_{e}\right)$. The investigation of the engine operation should be studied under the unsteady - state conditions. The only indication of the unsteady - state conditions is the variation of engine power with one, several or all engine parameters and time, i.e.

$$
N_{e}=f\left(T, \omega, P_{b}, g_{e}, \alpha, \eta_{e}, t\right)
$$

The dynamic properties of engine prime mover are characterized by the following differential equation:

$$
J \frac{d \omega}{d t}=T-T_{l}
$$


The current values of the parameters of the above equation are:

$$
\omega=\omega_{o}+\Delta \omega, T=T_{o}+\Delta T, T_{l}=T_{l o}+\Delta T
$$

Substituting the variables current values into equation, we get:

$$
J \frac{d \Delta \omega}{d t}=\Delta T-\Delta T_{l}
$$

The reduced mass moment of inertia is calculated by simplifying the engine to a simple slider crank mechanism and a complete kinematic and kinetic analysis should be investigated [13].

The load torque depends on the angular velocity $\omega$ and the load setting $N$ (the road slope, type of terrain, etc.....), i.e.

$$
T_{l}=f(\omega, N)
$$

This equation is non - linear, but at low $\Delta \omega$, this equation may be linearly approximated using Taylor series expansion, this gives:

$$
\Delta T_{l}=\frac{\partial T_{l}}{\partial \omega} \Delta \omega+\frac{\partial T_{l}}{\partial N} \Delta N
$$

In this model, the applied load settings are the coefficient of rolling resistance and the road slope angle, so equation (23) will be

$$
\Delta T_{l}=\frac{\partial T_{l}}{\partial \omega} \Delta \omega+\frac{\partial T_{l}}{\partial f} \Delta f+\frac{\partial T_{l}}{\partial \alpha} \Delta \alpha
$$

The relationship between the load torque of engine and the angular velocity is given from following equation:

$$
\begin{aligned}
& T_{l}=\frac{f_{c} G r_{d . s}}{i_{T} \eta_{T}} \\
& f_{c}=f \cos \alpha+\sin \alpha
\end{aligned}
$$

The relationship between the load torque and the load settings can be calculated from the following equation:

$$
T_{l}=\frac{f_{c} G r_{d . s}}{i_{T} \eta_{T}}
$$


Back to equation (21), the engine torque depends on cycle fuel supply $\left(g_{\text {cyl }}\right)$ and completeness of fuel combustion. The latter depends on the amount of air supplied into the combustion chamber. Since the cycle fuel supply is determined by the position (h) of the throttle as well as by the angular velocity $(\omega)$, and the boost pressure $\left(P_{b}\right)$. But the vehicle engine is a normally aspirated engine, i.e. without a turbocharger, so $P_{b}=0$, so we have:

$$
T=f(h, \omega)
$$

The expansion of this equation into a Taylor series gives:

$$
\Delta T=\frac{\partial T}{\partial h} \Delta h+\frac{\partial T}{\partial \omega} \Delta \omega
$$

The relationship between engine torque and angular velocity is known from the engine performance characteristics.

The relationship between engine power and accelerator position is calculated from the following equation, [4]

$$
\begin{array}{ll}
p=0.2 y & \mathrm{y} \leq 50 \\
p=10+1.8(y-50) & \mathrm{y}>50
\end{array}
$$

Since the relationship between engine power and engine torque is known, so using the previous equation, the relationship between engine torque and accelerator displacement can be determined and can be calculated

Substituting by equations (24) and (29) into equation (21), this gives:

$$
T_{e}\left(\frac{d \varphi}{d t}\right)+k_{e} \varphi=\chi-\theta_{e 1} \alpha_{e 1}-\theta_{e 2} \alpha_{e 2}
$$

where:

$$
\begin{aligned}
& T_{e}=J\left(\frac{\partial h}{\partial T}\right)\left(\frac{\omega_{o}}{h_{o}}\right) \\
& k_{e}=F_{e}\left(\frac{\partial h}{\partial T}\right)\left(\frac{\omega_{o}}{h_{o}}\right) \\
& F_{e}=\left(\frac{\partial T_{l}}{\partial \omega}-\frac{\partial T}{\partial \omega}\right) \Delta \omega \\
& \theta_{e l}=\left(\frac{\partial T_{l}}{\partial N}\right)\left(\frac{\partial h}{\partial T}\right)\left(\frac{f_{o}}{h_{o}}\right)
\end{aligned}
$$




$$
\begin{aligned}
\theta_{e 2} & =\left(\frac{\partial T_{l}}{\partial N}\right)\left(\frac{\partial h}{\partial T}\right)\left(\frac{\alpha_{o}}{h_{o}}\right) \\
\varphi & =\frac{\Delta \omega}{\omega_{o}}, \chi=\frac{\Delta h}{h_{o}}, \alpha_{e 1}=\frac{\Delta f}{f_{o}}, \alpha_{e 2}=\frac{\Delta \alpha}{\alpha_{o}}
\end{aligned}
$$

All the above equations were used in the hydraulic subsystem simulink model as shown in Fig. 13.

\section{SYSTEM VALIDATION}

The validation procedure consists of comparing the output of the model and the output of the real system under the same input. Several inputs were used in order to analyze the entire spectrum of the output pressure and rack displacement. Fig. 1518 shows the comparison between measured and simulated results for representative values of the system.

A ramp signal is applied to the system instead of the input of joystick slider. It corresponds to accelerator fuel and engine speed. Figures 14 and 15 show the comparison between measured and simulated results for the engine speed and pedal displacement of the system. As shown in these results, the engine speed increases slowly for about half of the stroke of the fuel pedal and then it increases rapidly, and this increasing will be sensitive to a fuel pedal position. The slow increase is due to the inertia of pedal and its mechanical control linkage. These results are similar to the results given in 0.

\section{Effect of PID Controller}

Experimental measurements show a small overshoot in the engine speed and accelerator displacement. Adding a PID controller will eliminate this overshoot, the values of the PID gains are:

$\mathrm{K}_{\mathrm{P}}=8 \quad \mathrm{~K}_{\mathrm{I}}=0.015 \quad \mathrm{~K}_{\mathrm{D}}=0.0095$

The effect of PID controller on engine speed and pedal displacement is measured at different speeds (1000, 1500, 2000 and $2500 \mathrm{rpm})$. Figure 16 shows the effect of PID controller at $1500 \mathrm{rpm}$ but this effect isn't clear, so the magnification of that effect is presented in Fig. 17. It is clear that the PID controller will eliminate the overshoot, improve the rise time and decrease the steady state error of the control system.

\section{Effect of Changing of Command Signal to P.D.C.V}

In the previous measurements, the command signal (that controls the motion of the spool of the PDCV) is constant and equal to 4V. Measuring the engine speed and pedal displacement at different voltages has been shown in Fig. 18 and Fig. 19. It is clear that increasing the input voltage will increase the rise time of the hydraulic cylinder and consequently the rise time of engine speed. 


\section{CONCLUSION}

The research outlined in this paper has demonstrated the implementation of the fuel pedal control system for a remotely operated vehicle.

A dynamic model of a power steering system is developed and the simulation results were found to agree to a great extent with the real test results.

New proportional directional control valves are equipped with a built - in controller and spool position feedback increases the response and accuracy and approaching the servo valves, and still less cheap than the servo valves.

The developed engine model can be easily adapted to fit in any tracked vehicle equipped with ICE but with some variations in some parameters.

The introduction of robotics and artificial intelligence technology can result in a number of benefits, among them are the following: Improved combat capabilities, minimized exposure of persons to hazardous environments, increased mission flexibility, increased system reliability, reduced unit/life-cycle costs, reduced manpower requirements and simplified training.

\section{REFERENCES}

[1] Durrant H. "A Critical Review of the State of the Art in Autonomous Land Vehicle Systems and Technology" SANDIA REPORT 2001, Sandia International Laboratories, USA, 2001.

[2] Wang J. Y "Theory of Ground Vehicles (2nd Edition)". John Wiley, London, 1993

[3] Boon N. K., Choo T. H., and Wah C. C. "Autonomous Unmanned Ground Vehicle and Indirect Driving" Data Horizons 2005.

[4] Gong Z., Guzman J. I., Scheding S. J., Rye D. C., Dissanayake G., Whyte H. D. "A Heuristic Rule - Based Switching and Adaptive PID Controller for a Large Autonomous Tracked Vehicle: Form Development to Implementation" Proceedings of the 2004 IEEE, International Conference on Control Applications, PP 1277 - 1277, Taiwan. April 2004.

[5] Morillon J. G., and Lecointe O. "SYRANO: A Ground Robotic System for Target Acquisition and Neutralizatio" Proceedings of SPIE, Vol. 5083, Aero Sense 2003, Unmanned Ground Vehicle Technology V, April 2003.

[6] Schwartz I., "PRIMUS Autonomous Driving Robot for Military Applications" Proceedings of SPIE, Vol. 4024, PP 313 - 325, Aero Sense 2000, Unmanned Ground Vehicle Technology II, April 2000.

[7] Wang G. G., Wang S. H. and Chen C. W. "Design of a Turning Control for a Tracked Vehicle" IEEE Control System mMagazine, Vol. 10, No. 3 P.P 122 125, April 1990.

[8] Nitao J. J. and Paradi A. M. "A Teal - Time Reflexive Pilot for an Autonomous Land Vehicle", IEEE Control System Magazine, Vol. 6, No. 1, PP $14-23$, Feb. 1986. 
[9] Atef M., Elhaddad M.I., Khodary R. H., and Eliewa A. E., A Proposed Control System for Autonomous Unmanned Ground Vehicle, Proceedings of $13^{\text {th }}$ Int ASAT Conference, 26 - 28 May 2009.

[10] Atef M., Elhaddad M.I., Khodary R.H., and Eliewa A.E., "Modeling and Simulation of a Control System for a Remotely Operated Tracked Vehicle" Proceedings of $14^{\text {th }}$ Int. AMME Conference, 27-29 May 2010.

[11] Rabie M. G. "Fluid Power Engineering", McGraw - Hill, New York, 2009

[12] Krutov V. I. "Automatic Control of Internal Combustion Engines" 1st Edition, Mir Publishers Moscow. 1987.

[13] Norton R. L., Design of Machinery, an Introduction to Synthesis and Analysis of Mechanisms and Machines, 3rd Edition, WCB / McGraw - Hill Inc., U.S.A, 2004

[14] Technical Manual for Direct Support and General Support Maintenance engine, (TM9-2815-205-34), Washington, Sep. 1991.

\section{LIST OF FIGURES}

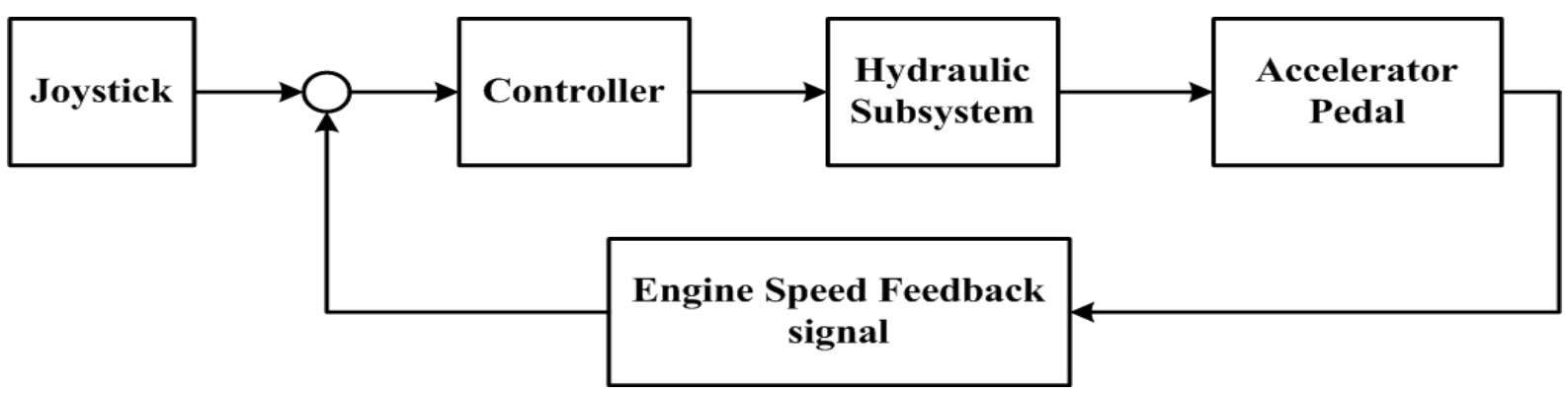

Fig. 1. Fuel pedal control system block diagram.

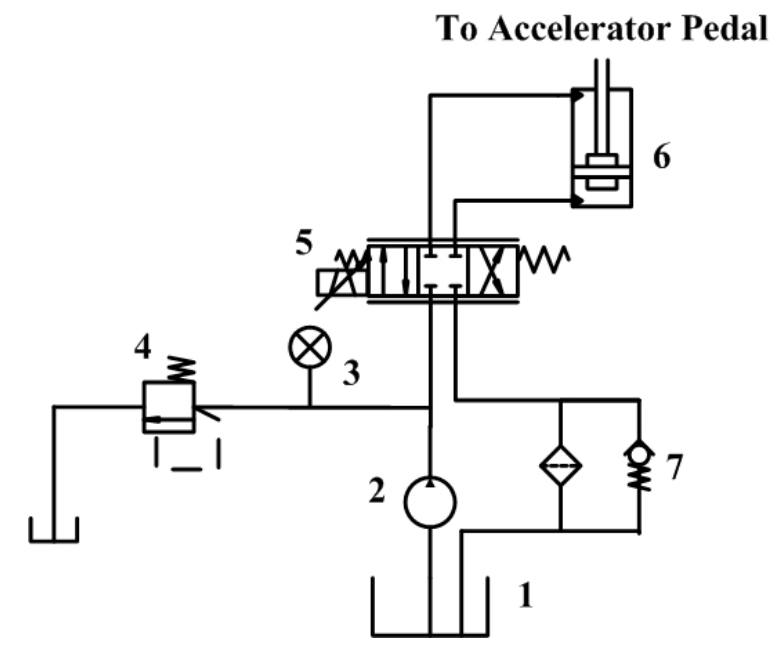
1 Fluid tank
2 Pump
3 Pressure indicator
4 Relief valve
5 Proportional directional
6 Hydraulic cylinder
7 Filter with bypass valve

Fig. 2. The designed hydraulic circuit. 


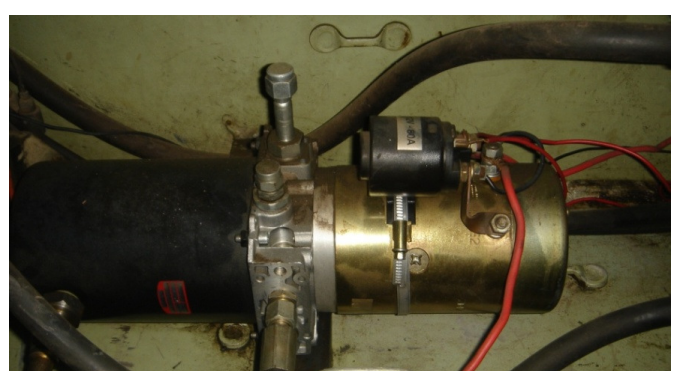

Fig. 3. Hydraulic Pump and its driven motor.

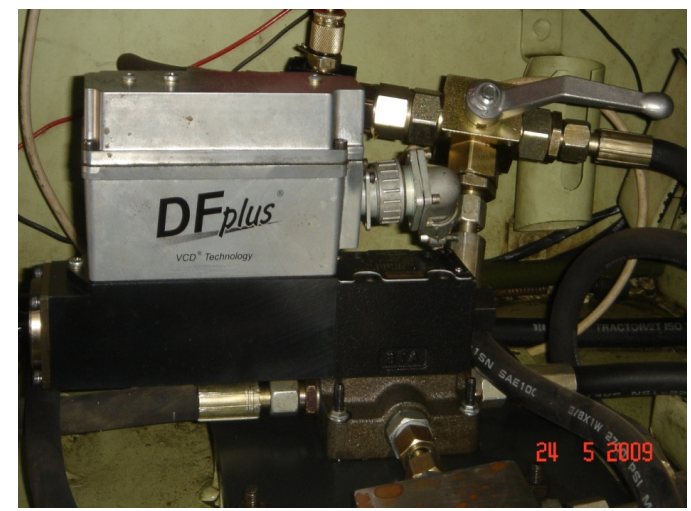

Fig. 5. The used P.D.C.V.

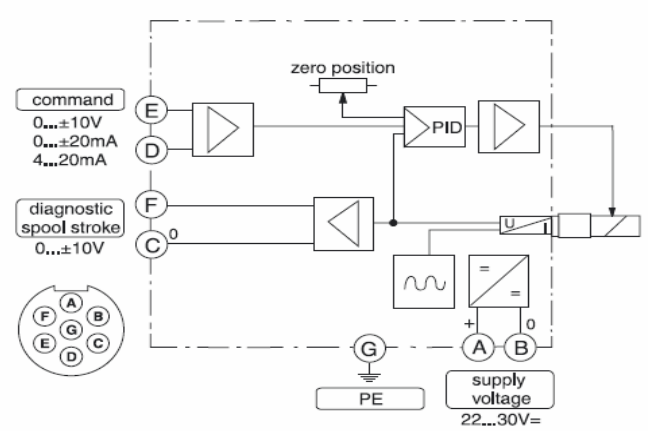

Fig. 4. Control circuit of P.D.C.V.

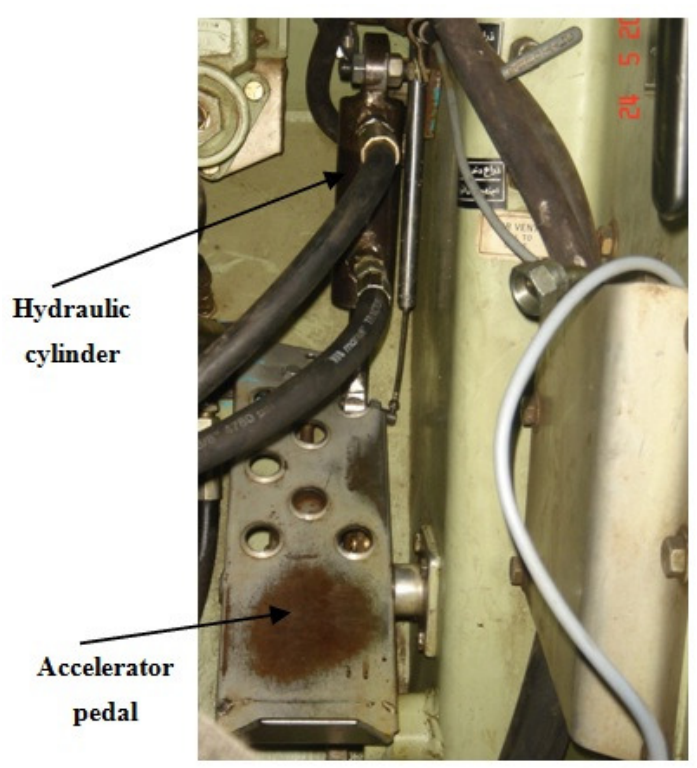

Fig. 6. Setup of hydraulic cylinder with the accelerator pedal.

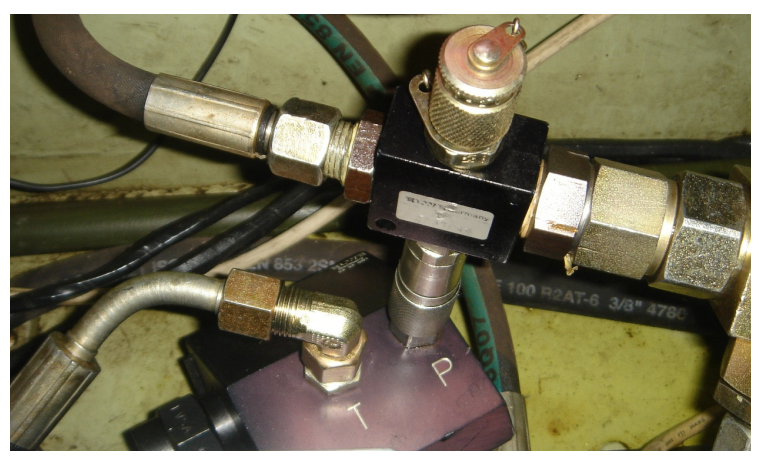

Fig. 7. The used relief valve. 

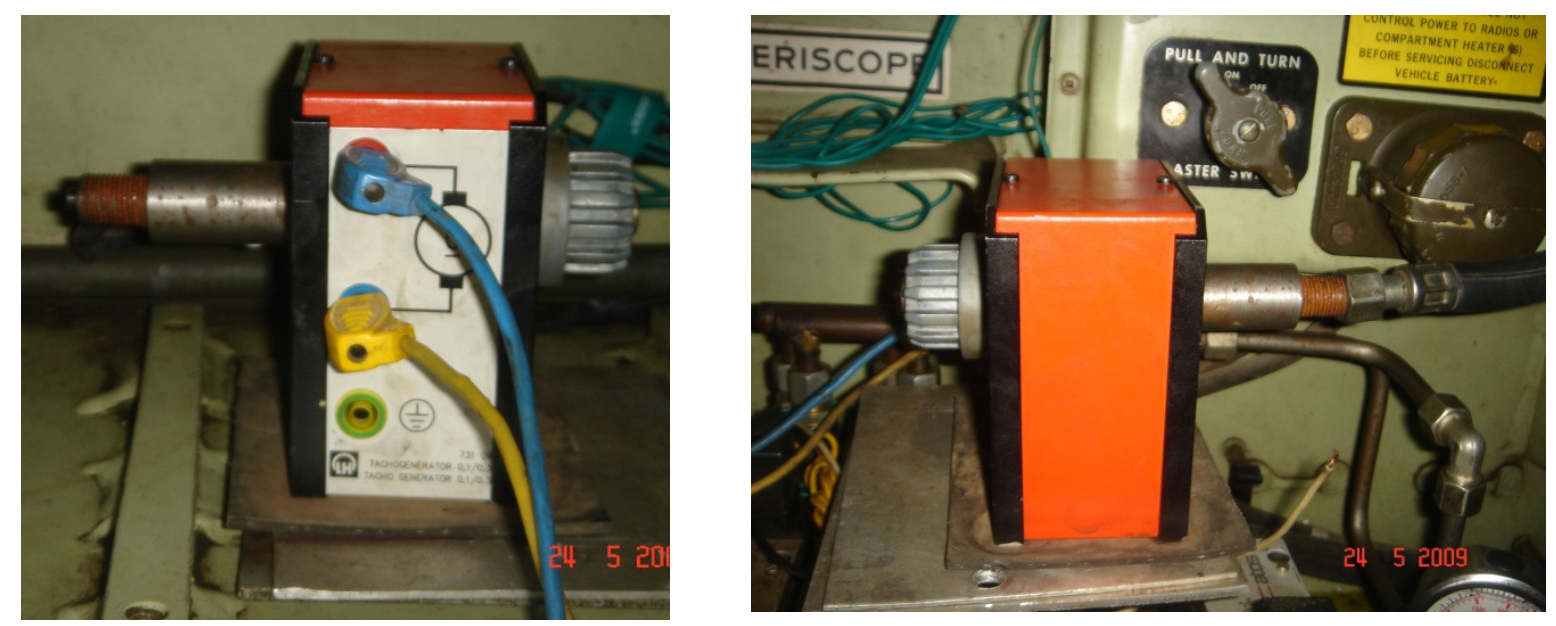

Fig. 8. DC tachometer and its adaptation with the tachometer wire.
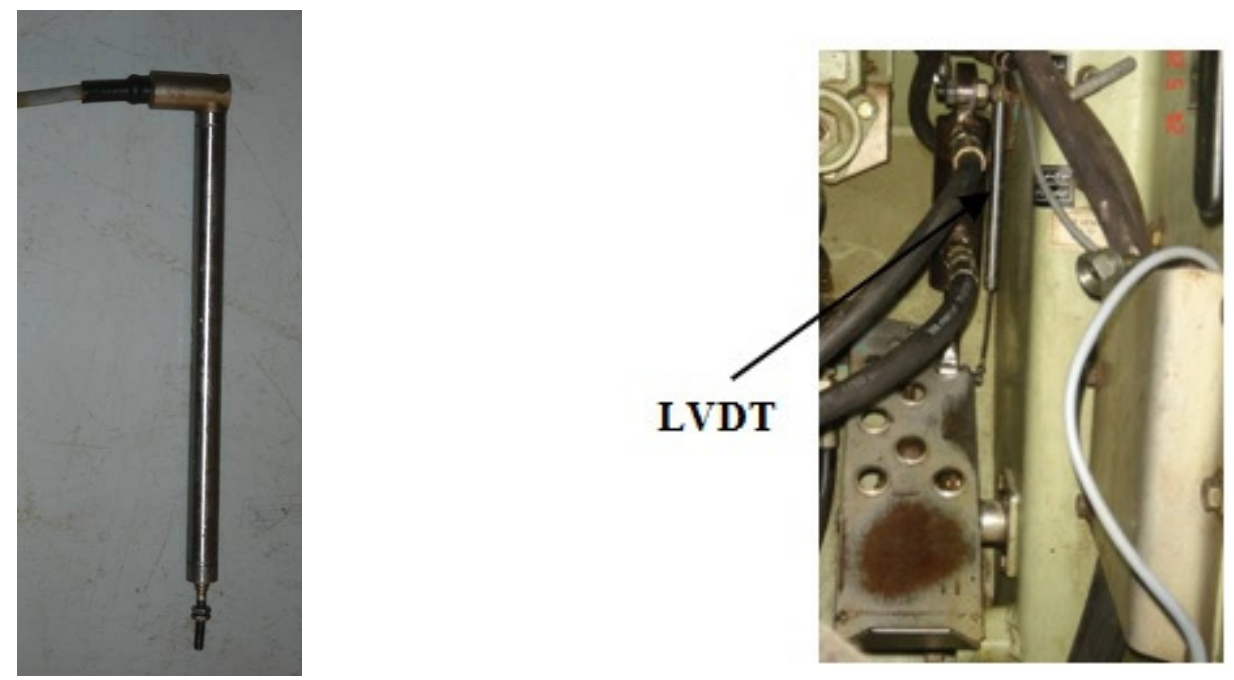

Fig. 9. The used LVDT and its connection with the fuel pedal.

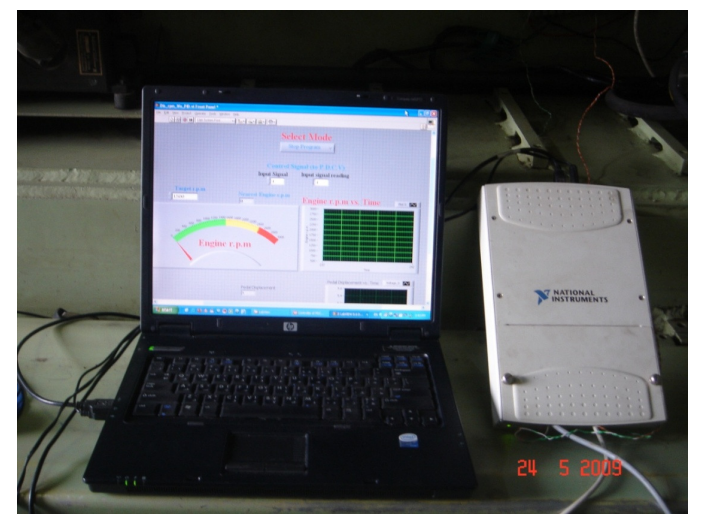

Fig. 10. Interface of the PC and the DAQ. 


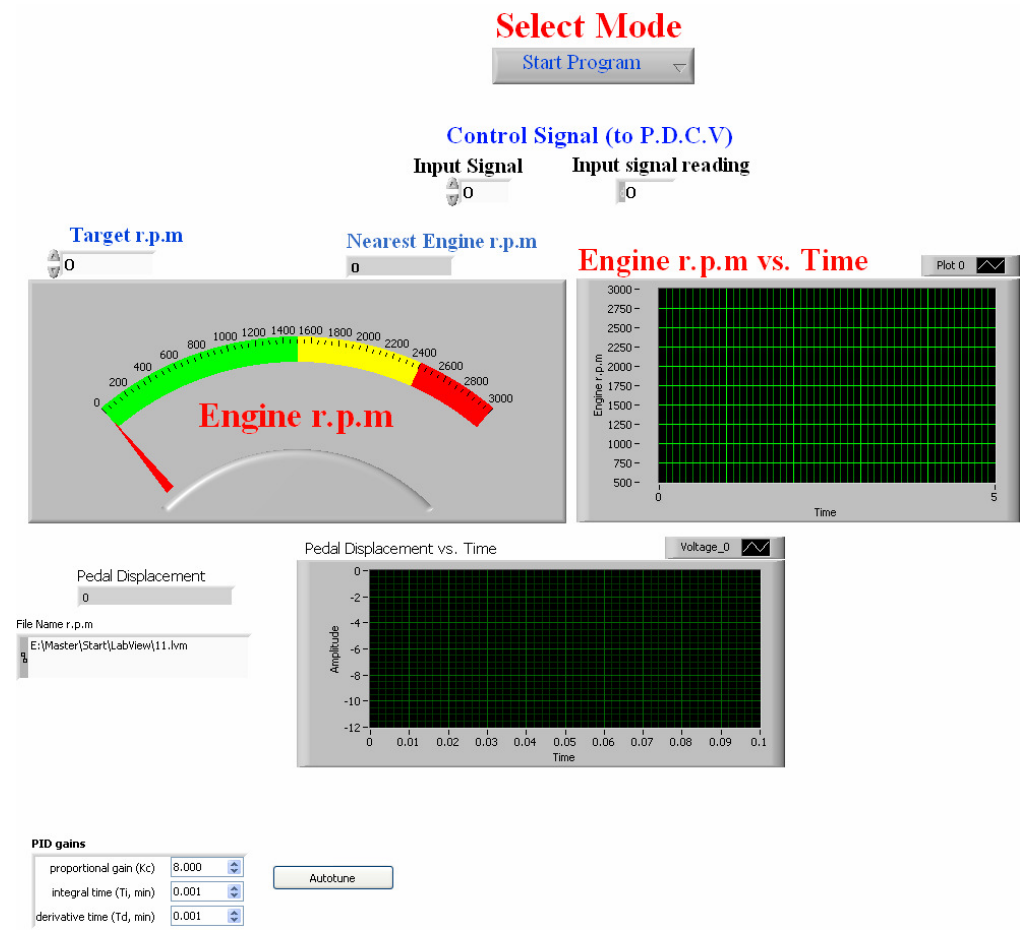

Fig. 11. Labview front panel.

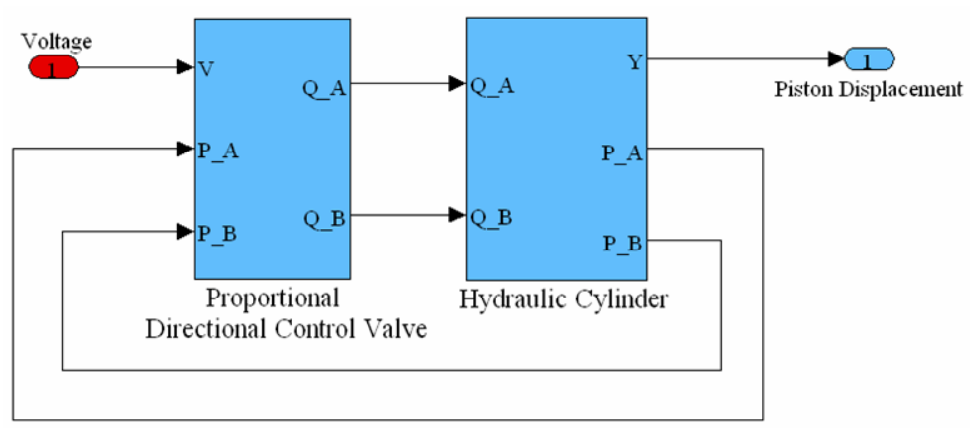

Fig. 12. Hydraulic subsystem Simulink model.

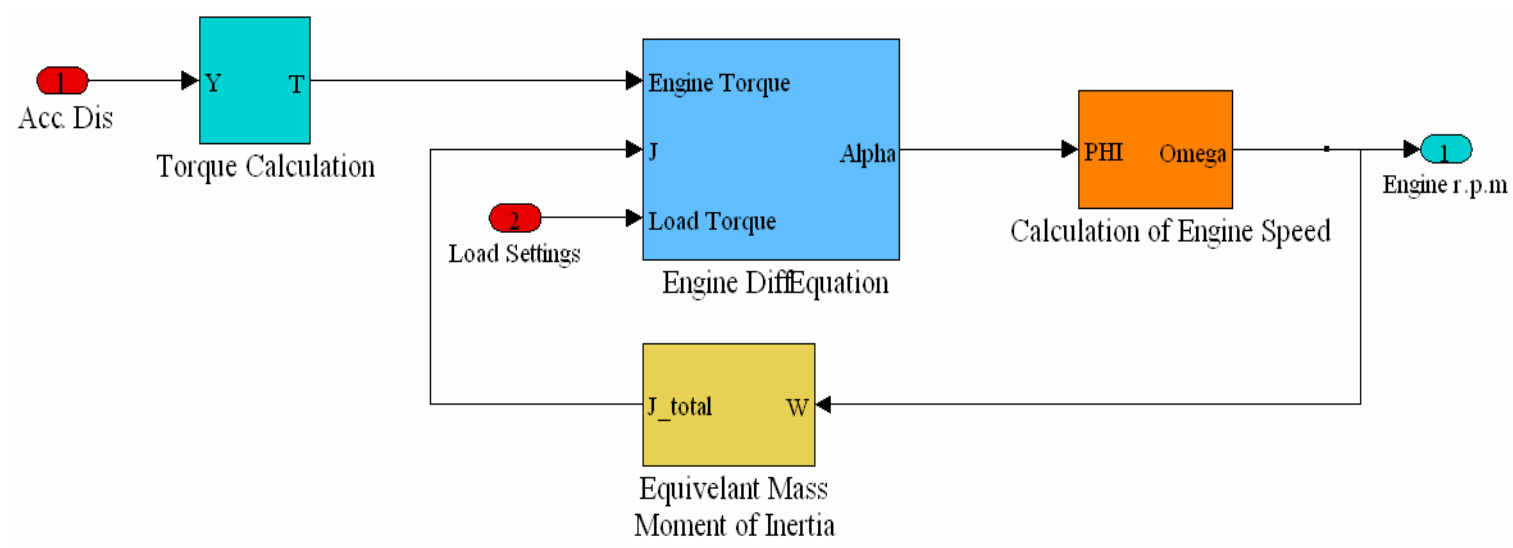

Fig. 13. Engine Simulink model. 


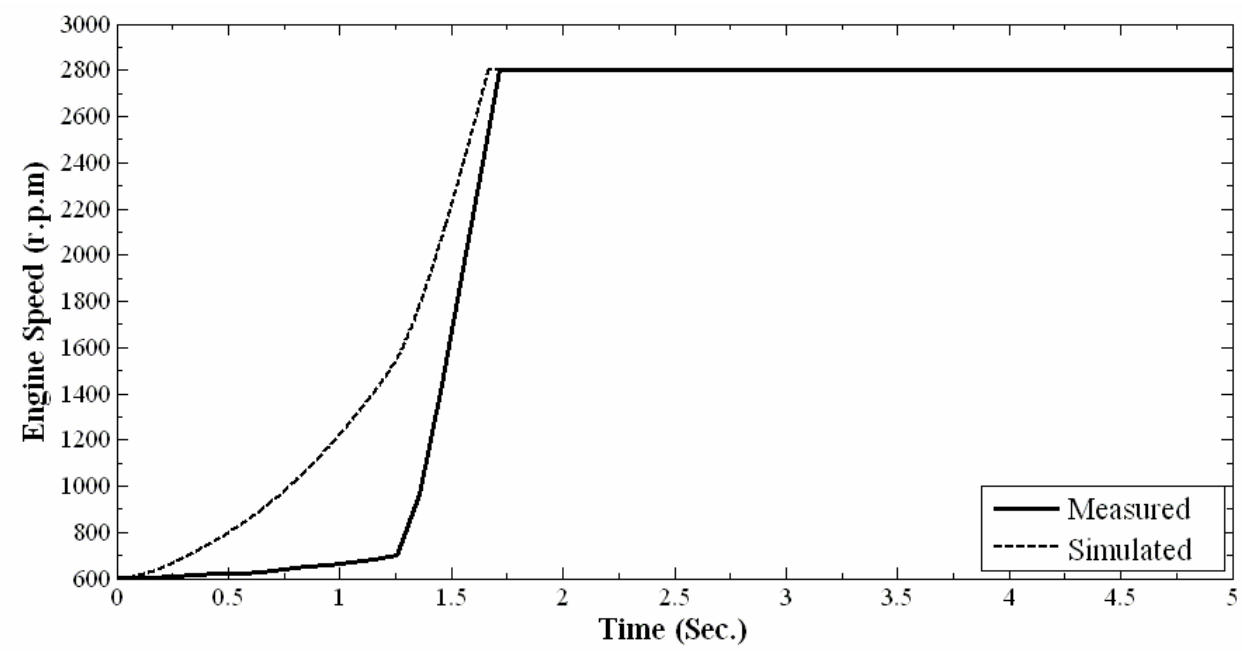

Fig. 14. Measured and simulated results for engine speed.

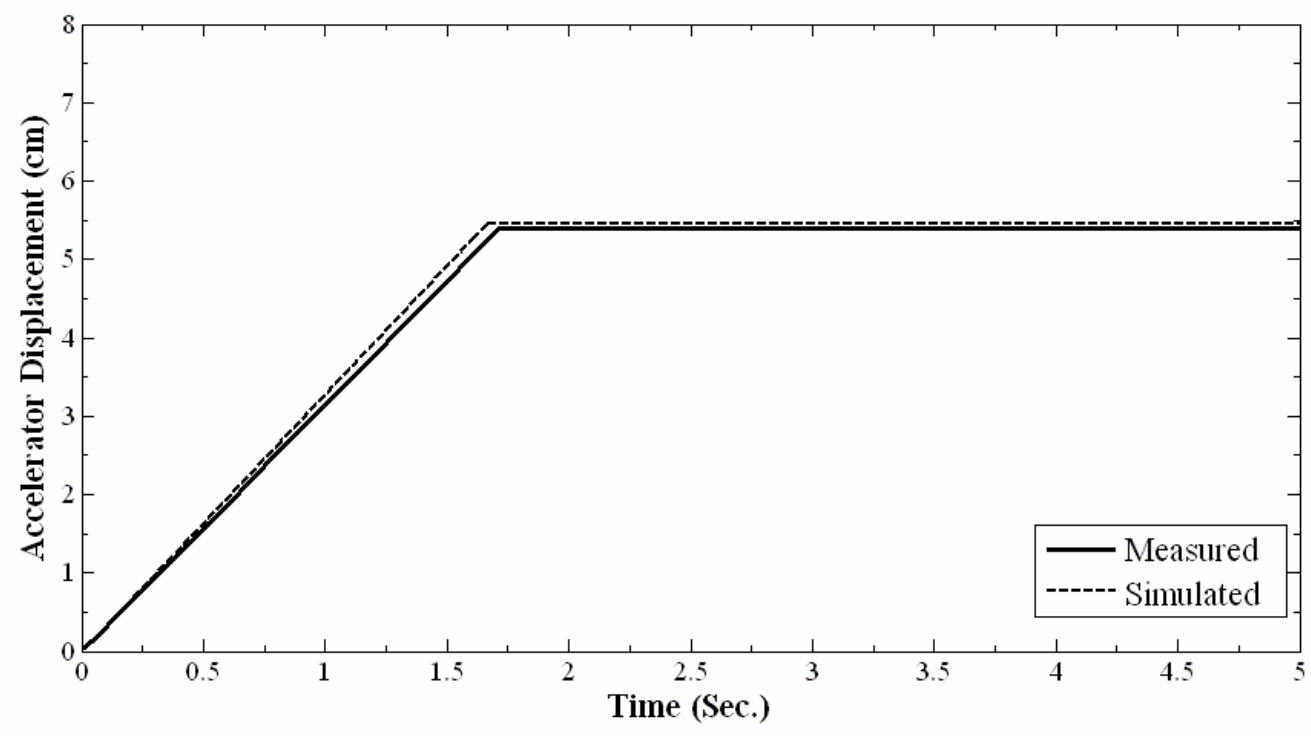

Fig. 15. Measured and simulated results for pedal displacement.

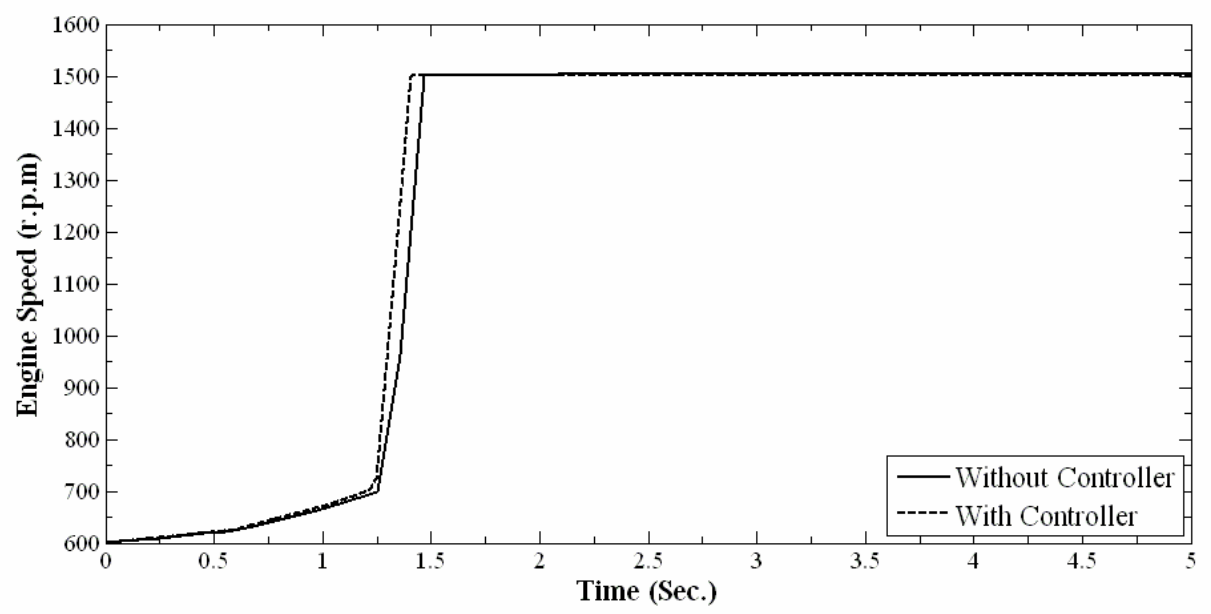

Fig. 16. Effect of PID controller on Engine speed at 1500 r.p.m. 


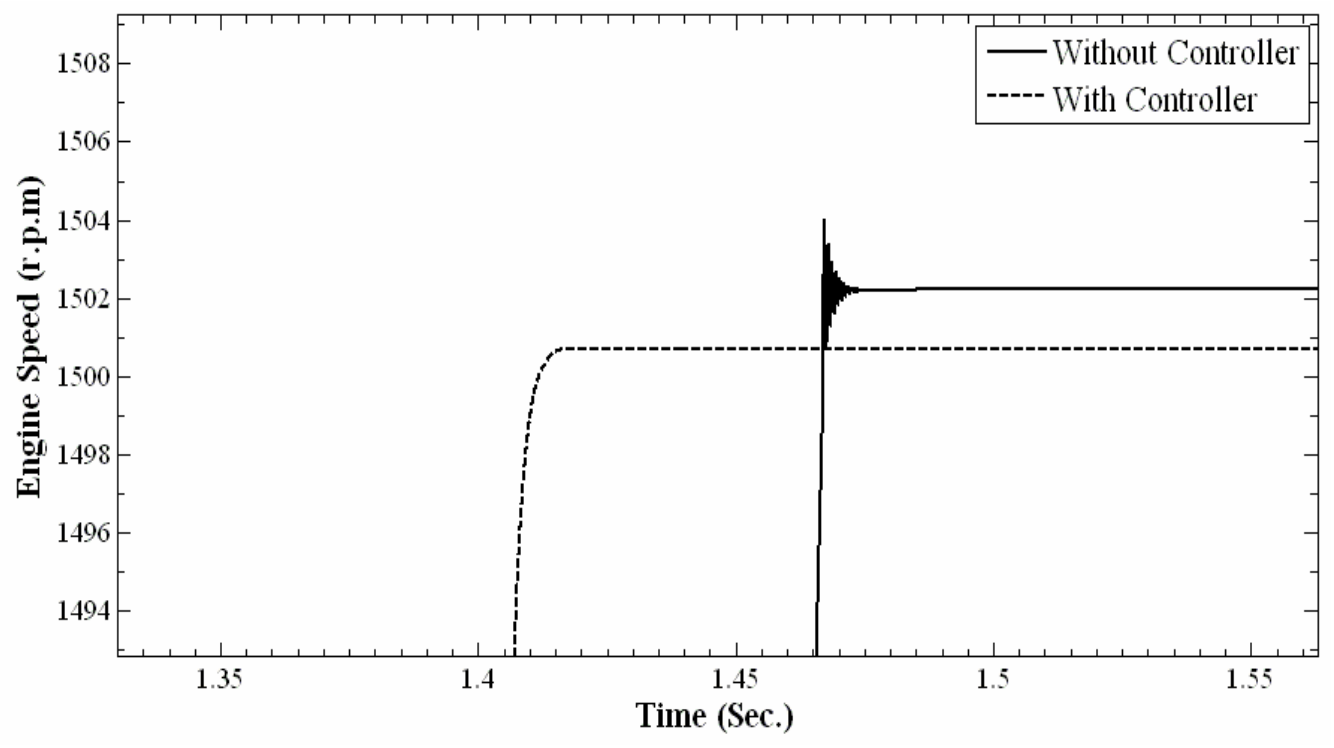

Fig. 17. Magnification of effect of PID controller on engine speed at 1500 r.p.m.

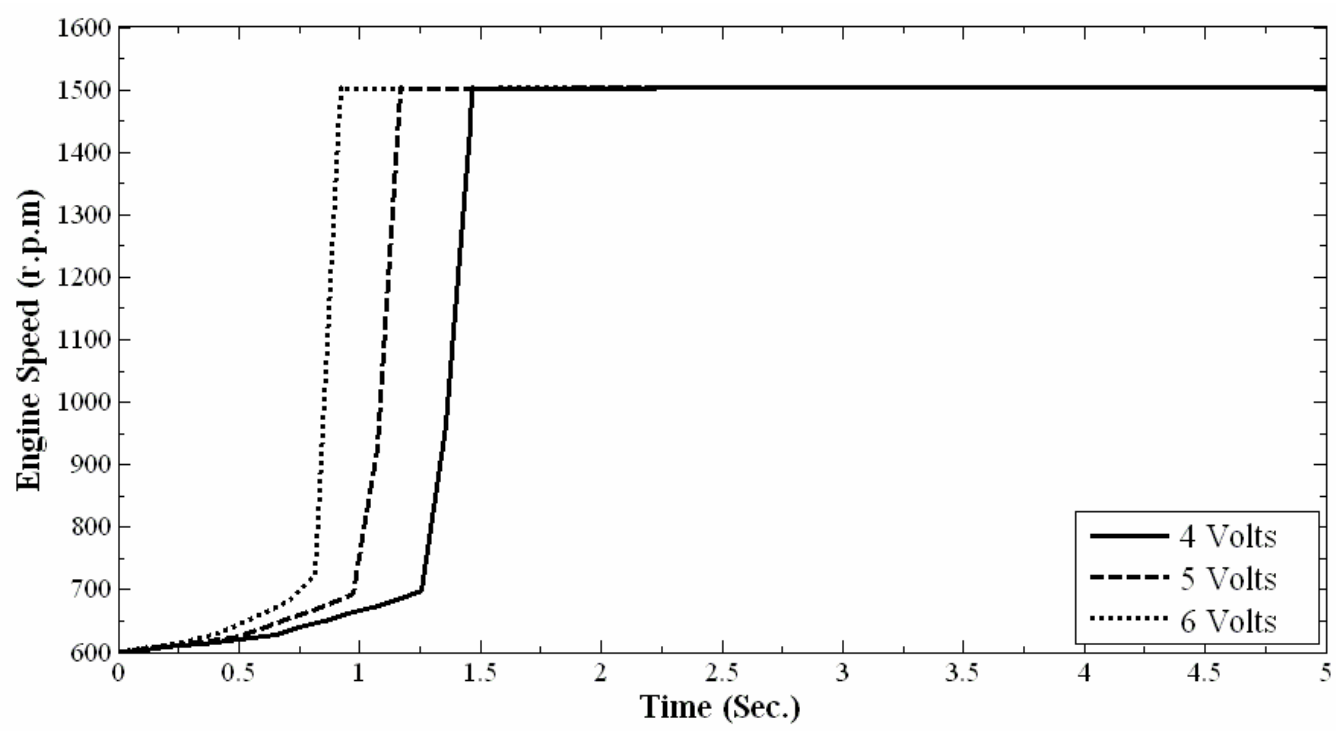

Fig. 18. Effect of changing the command signal of the PDCV on engine speed.

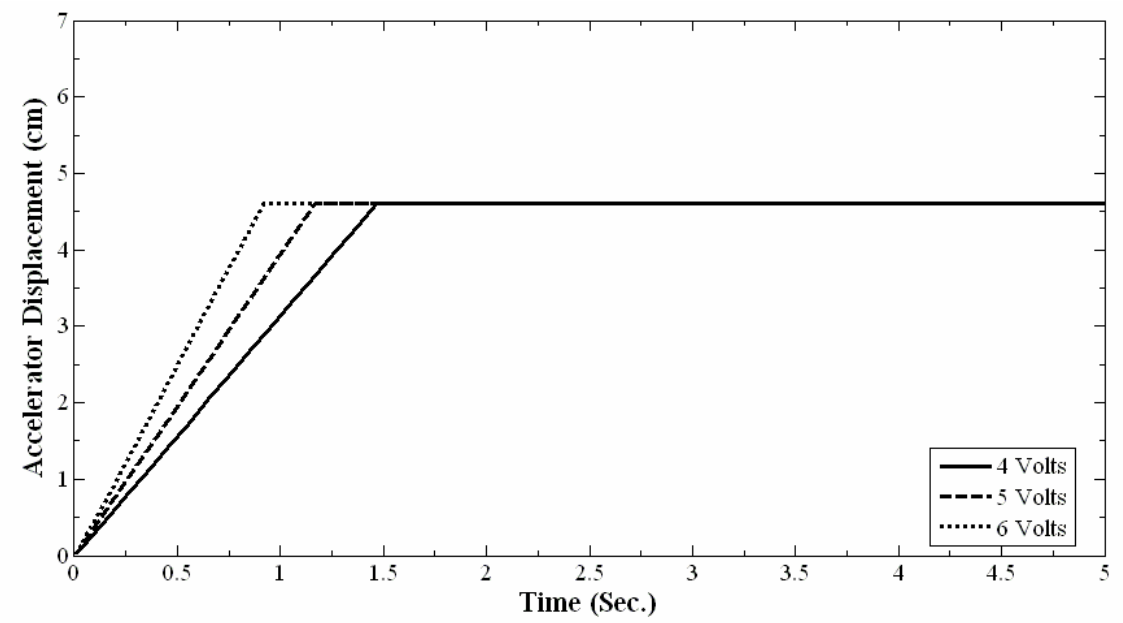

Fig. 19. Effect of changing the command signal of the PDCV on pedal displacement. 